\title{
Xantogranuloma de los plexos coroideos y sus diagnósticos diferenciales
}

\section{Xantogranuloma of the Choroid Plexus}

\section{Diego Páez-Granda ${ }^{1}$ Sebastián Rivadeneira-Rojas²}

${ }^{1}$ Servicio de Radiodiagnóstico, Hospital Universitario Virgen de la Arrixaca, Murcia, España

2 Servicio de Radiodiagnóstico, Hospital Juan A. Fernández, Buenos Aires, Argentina

Rev Argent Radiol 2018;82:181-183.

Estimados Editores,

Los tumores amarillos o xantogranulomas de los plexos coroideos son quistes benignos no inflamatorios. Así es como por primera vez fueron descritos por Blumer en $1900 .{ }^{1}$ Esas lesiones han llamado nuestra atención y es por esa razón que queremos exhibir el caso de una mujer previamente sana de 39 años de edad, que tras referir un episodio de cefalea intensa se le realizó una tomografía computada (TC), donde se identificaron unas lesiones hipodensas en ambos cuerpos coroideos. Luego

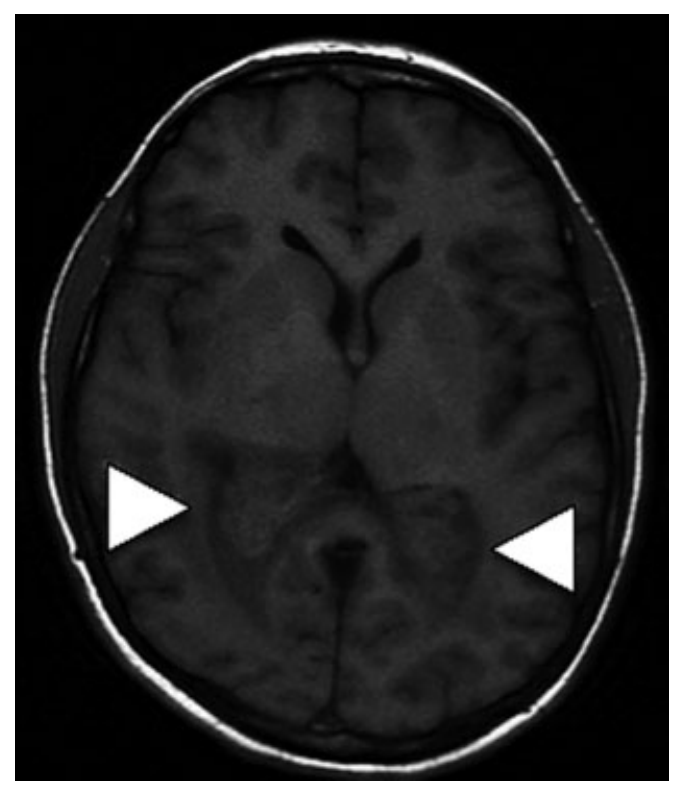

Fig. 1 Secuencia ponderada en T1. Existen lesiones bilaterales isointensas a la sustancia blanca centradas en el plexo coroideo de los cuernos occipitales.

received June 17, 2017 accepted December 30, 2017 published online April 12, 2018
Address for correspondence S. Rivadeneira-Rojas, Médico Residente, Hospital Juan A. Fernández, Buenos Aires, Argentina (e-mail: rr.sebastian@hotmail.com).

del estudio tomográfico se procedió a realizar una resonancia magnética (RM), y se evidenció que tales lesiones se trataban de "tumores amarrillos" de los plexos coroideos. A continuación, expondremos una breve síntesis de la patología que nos condujo a dar con su diagnóstico radiológico.

Hoy en día se sabe que por su patogénesis el término adecuado es xantogranuloma, porque la lesión no es una neoplasia, sino que es un cúmulo de reacciones histiocíticas a los lípidos, que contienen células espumosas en racimos

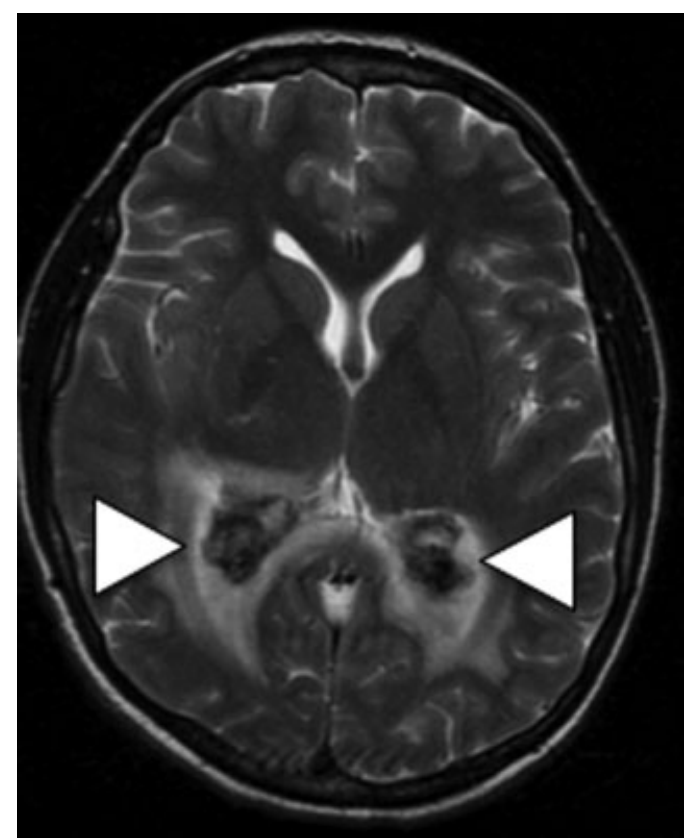

Fig. 2 Secuencia ponderada en T2: lesiones hipointensas.

Copyright (c) 2019, Sociedad Argentina de Radiología. Publicado por Thieme Revinter Publicações Ltda., Rio de License terms $10.1055 / \mathrm{s}-0038-1641133$ ISSN 1852-9992. Janeiro, Brazil. Todos los derechos reservados. 
formadas a partir de linfocitos y macrófagos, que en su interior presentan depósitos de cristales de colesterol. ${ }^{2,3}$ Esa lesión es de presentación infrecuente, y la prevalencia de ese hallazgo oscila entre el $1 \%$, con una edad promedio de aparición a partir de los 40 años. Igualmente, se ha determinado una tendencia de 3:1 entre hombres y mujeres respectivamente y se ha visto que la mayoría de xantogranulomas se producen dentro de los ventrículos laterales. ${ }^{1}$

En nuestro caso, se trata de una paciente sin antecedentes patológicos; que frente a un episodio de cefalea aguda, se le solicitó una TC. Como hallazgo incidental encontramos áreas hipodensas en los cuerpos coroideos de forma bilateral. Inmediatamente, se realizó una RM que en las secuencias ponderadas en T1 son isointensas ( - Fig. 1), y las ponderadas en T2 hipointensas ( $\mathbf{- F i g . ~} 2$ y $\mathbf{3}$ ), con fuerte realce luego de la inyección del contraste, con restricción en la secuencia de difusión y disminución de la intensidad de señal en el mapa de coeficiente de difusión aparente (ADC) (-Fig. 4).

Este caso nos llevó a investigar sobre los tipos de tumores de esa localización. ${ }^{3}$ Podemos considerar que los diagnósticos diferenciales son: el papiloma del plexo coroideo, el carcinoma del plexo coroideo, las metástasis, el meningioma intraventricular y la histiocitosis. ${ }^{4-6}$ La edad de la paciente descarta el papiloma, debido a que ese tumor es casi exclusivo de la edad pediátrica, la localización bilateral puede excluir carcinoma primario y meningioma de la lista de diagnósticos, la normalidad del infundíbulo hipotalámico ayuda a excluir la histiocitosis y la ausencia de antecedentes de un tumor primario descarta metástasis. ${ }^{3-5}$

Pudimos concluir que los xantogranulomas de los cuerpos coroideos son acúmulos celulares de contenido graso, que no se degeneran en forma maligna. Sin embargo, debido a la ubicación,

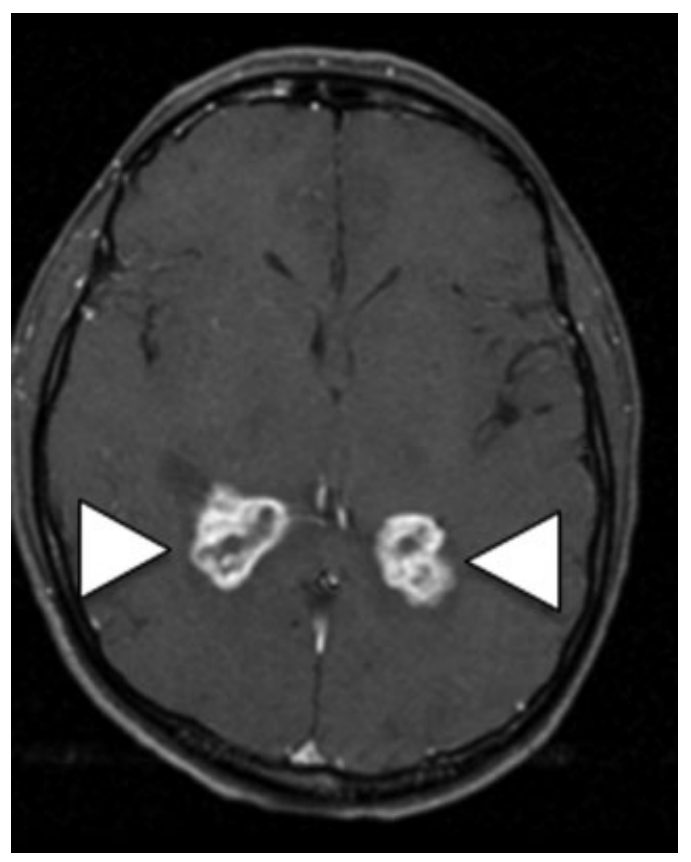

Fig. 3 Secuencia ponderada en $\mathrm{T} 1$ después de la administración del contraste. Las lesiones muestran fuerte realce tras la administración del contraste.

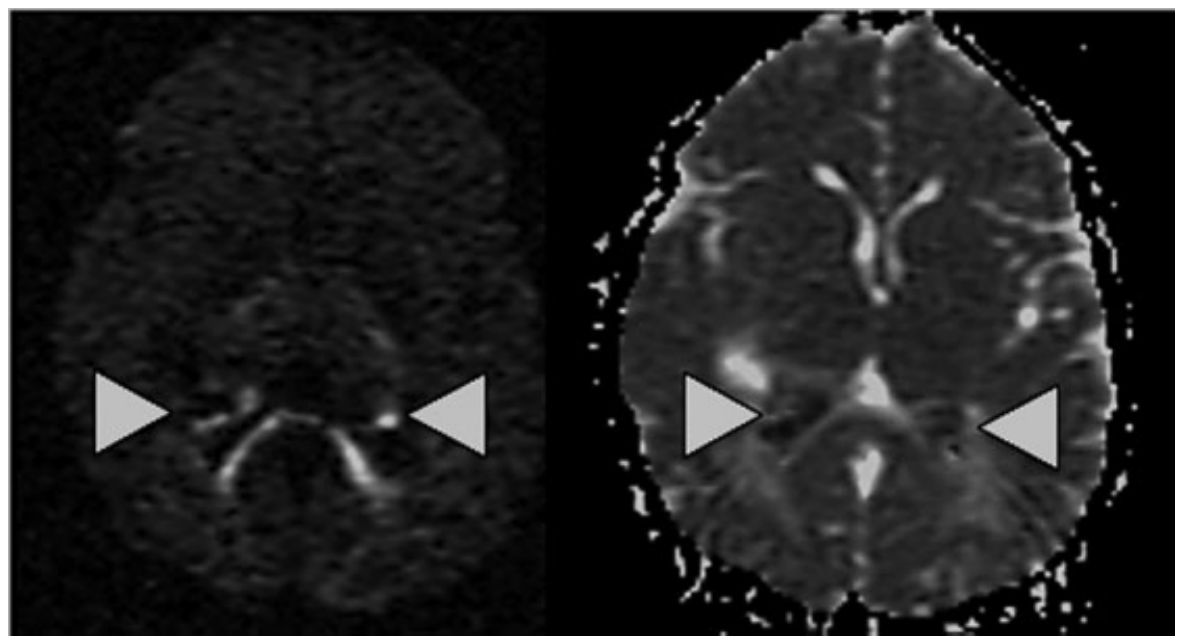

Fig. 4 Difusión (izquierda) y mapa de coeficiente de difusión aparente (ADC) (derecha). Las lesiones contienen estructuras hiperintensas lineales en secuencias con difusión (DWI), que corresponden a la hipointensidad en los mapas ADC (restricción). 
pueden causar hidrocefalia. Por tal motivo, el médico imagenólogo debe considerar ese diagnóstico cuando se enfrenta a lesiones de presentación bilateral en esa localización.

\section{Confidencialidad de Los Datos}

Los autores declaran que han seguido los protocolos bioéticos previa elaboración de este trabajo académico. El paciente ha recibido información suficiente y ha dado su consentimiento informado por escrito.

\section{Los autores Declaran}

Que no existe fuente de financiación.

\section{Conflicto de Intereses}

Los autores declaran no tener ningún conflicto de intereses.

\section{Referencias}

1 Shuangshoti S, Netsky MG. Xanthogranuloma (xanthoma) of choroid plexus. The origin of foamy (xanthoma) cells. Am J Pathol 1966;48(03):503-533

2 Shetty J, Devadiga KChandrika, Pai M. Unusual presentation of xanthogranuloma of the choroid plexus. J Neurosci Rural Pract 2010;1(02):97-98

3 Pear BL. Xanthogranuloma of the choroid plexus. AJR Am J Roentgenol 1984;143(02):401-402

4 Kadota T, Mihara N, Tsuji N, Ishiguro S, Nakagawa H, Kuroda C. MR of xanthogranuloma of the choroid plexus. AJNR Am J Neuroradiol 1996;17(08):1595-1597

5 Kinoshita T, Moritani T, Hiwatashi A, et al. Clinically silent choroid plexus cyst: evaluation by diffusion-weighted MRI. Neuroradiology 2005;47(04):251-255

6 Osborn AG, Salzman KL, Barkovich AJ. Diagnostic imaging: brain. Salt Lake City: Amirsys; 2010 